\title{
Effect of Temperature, Electrode Potential, and Bulk Composition on Hydrogen Electrosorption into Palladium-Ruthenium Alloys-Comparative Study with Other Binary Systems
}

\author{
Katarzyna Hubkowska ${ }^{1}$ (D) Mariusz Łukaszewski ${ }^{1}$ • Andrzej Czerwiński ${ }^{1,2}$
}

Published online: 23 January 2018

(C) The Author(s) 2018. This article is an open access publication

\begin{abstract}
The influence of temperature between $283 \mathrm{~K}$ and $328 \mathrm{~K}$ on hydrogen electrosorption into Pd-Ru alloys in the bulk composition range $87-100 \%$ at. Pd was studied voltammetrically and chronoamperometrically in $0.5 \mathrm{M} \mathrm{H}_{2} \mathrm{SO}_{4}$ solution. The maximum alloy ability to absorb hydrogen decreases with increasing temperature. The extent of hydrogen absorption/desorption hysteresis is slightly reduced with increasing temperature and markedly reduced with increasing Ru bulk content. Both increasing temperature and Ru bulk content results not only in a decrease in the thermodynamic stability of the hydride phase but also in an improvement in the kinetics of hydrogen electrosorption. Pd-Ru alloys containing more than ca. 97\% at. Pd absorb more hydrogen than pure $\mathrm{Pd}$, while further Ru additive results in a significant deterioration of the alloy ability to absorb hydrogen. The data on the influence of temperature and alloy bulk composition on the processes of hydrogen electrosorption in Pd binary alloys with Ru, Rh, Pt, and Au have been compared.
\end{abstract}

Keywords Pd-Ru alloys $\cdot$ Hydrogen electrosorption $\cdot$ Temperature $\cdot$ Phase transition $\cdot$ Hysteresis

\section{Introduction}

In the whole group of Pd binary alloys, which are known as good catalysts and hydrogen absorbers [1-6], two systems deserve a special attention, namely Pd-Rh and Pd-Ru alloys. These systems are exceptional, because for certain composition ranges, the maximum amounts of absorbed hydrogen are greater than in the case of pure Pd [1-14], while other Pd alloys in their full composition range are always characterized by a weaker maximum ability to absorb hydrogen [1-6, 15-19]. In most Pd alloys, the gaps in the Pd d-band are filled by the electrons originating from the alloying metal, and therefore, less electronic states remain free for the electrons to be accepted from absorbing hydrogen, which leads to a

Katarzyna Hubkowska

khubkowska@chem.uw.edu.pl

1 Faculty of Chemistry, University of Warsaw, Pasteura 1, 02-093 Warsaw, Poland

2 Industrial Chemistry Research Institute, Rydygiera 8, 01-793 Warsaw, Poland deterioration of the absorption capacity [16]. Only for Pd-Rh and Pd-Ru alloys containing small amounts of Rh or Ru in the bulk, the number of gaps in the Pd d-band below the Fermi level is greater, which is manifested by an enhanced ability to absorb hydrogen [1-14].

The Pd-Rh system has been relatively well investigated, especially in recent years, and many of its electrochemical properties are now known, including those concerning hydrogen absorption phenomenon [7-10]. Also, the influence of surface poisons, like the products of $\mathrm{CO}_{2}$ and $\mathrm{CO}$ electrosorption, on the electrochemical processes of hydrogen adsorption, absorption, and desorption on/in/from Rhcontaining Pd alloys was thoroughly examined in our laboratory [20-22].

$\mathrm{Pd}-\mathrm{Ru}$ alloys, however, have rarely been studied [23-27], and just a few reports exist on hydrogen electrosorption in those materials [12-14, 28]. In order to fill this lack of scientific knowledge, we started in our laboratory a systematic examination of the electrochemistry of Pd-Ru alloys obtained as thin electrodeposits, i.e., limited volume electrodes (LVE) [12-14, 28].

In earlier papers devoted to the Pd-Ru system, we reported on the details of electrode preparation and characterization 
[28], hydrogen absorption in these alloys at room temperature $[12,13]$, and determination of the thermodynamic functions of the hydride phase formation [14]. Following our studies on the influence of temperature on the process of hydrogen electrosorption into Pd binary alloys with other noble metals (Au, Pt, and Rh), described in a series of articles [10, 29-31], we report here on the effect of temperature on the amount of hydrogen electrosorbed by $\mathrm{Pd}-\mathrm{Ru}$ of various bulk compositions. We present the influence of temperature and alloy composition on the potential of the voltammetric peak due to electrosorbed hydrogen oxidation $\left(E_{\mathrm{p}}{ }^{\mathrm{Hox}}\right)$, the potentials of the $\alpha \rightarrow \beta$ and $\beta-\alpha$ phase transitions $\left(E_{\alpha-\beta}\right.$ and $\left.E_{\beta-\alpha}\right)$, and the extent of absorption/desorption hysteresis. We also compare data for the Pd-Ru system with our earlier results obtained for other Pd-noble metal systems [8-10, 12-14, 29-32].

\section{Experimental}

Hydrogen absorption in $\mathrm{Pd}-\mathrm{Ru}$ alloys was performed under voltammetric and chronoamperometric conditions from $0.5 \mathrm{M}$ $\mathrm{H}_{2} \mathrm{SO}_{4}$ in the temperature range $283-328 \mathrm{~K}$. Analytical grade reagents (POCh, Poland) and purified water (applying Hydrolab and Millipore systems) were used for the preparation of solutions. In order to avoid the interference with dissolved oxygen, the electrolyte was deoxygenated by $\mathrm{Ar}$ (99.999\%) for $20 \mathrm{~min}$ prior to the experiments, while during the experiments, Ar was continuously passing above the solution level.

Three-electrode system was applied with a $\mathrm{Hg}\left|\mathrm{Hg}_{2} \mathrm{SO}_{4}\right| 0.5 \mathrm{M} \mathrm{H}_{2} \mathrm{SO}_{4}$ and a $\mathrm{Pt}$ gauze as the reference and auxiliary electrode, respectively. All potentials are expressed in the RHE scale according to the calculations described earlier [10]. A CH Instrument potentiostat (model 604) was used for the experiment performance, data acquisition, and their further treatment. The whole electrochemical cell was maintained in a given, constant temperature, controlled by a thermostat (Lauda RE 306, Germany).

Pd or Pd-Ru layers (thickness ca. $1.0 \mu \mathrm{m}$, i.e., LVE) electroplated on a gold wire $(99.99 \%, 0.5-\mathrm{mm}$ diameter) served as working electrodes. The alloys were prepared by a potentiostatic electrodeposition from baths obtained by mixing in various proportions the aqueous solutions of $\mathrm{PdCl}_{2}, \mathrm{RuCl}_{3}$, and $\mathrm{HCl}$. As we reported earlier [28], lower deposition potential resulted in higher Ru bulk concentration in the alloys. In order to determine Pd and Ru contents in the deposited alloys, the electrodes were analyzed by atomic emission spectroscopy after the electrochemical measurements.

We used the same procedures of hydrogen electrosorption and the calculations of the amount of absorbed hydrogen as those described earlier [8-10, 12-14, 29-32].

\section{Results and Discussion}

Typical cyclic voltammograms $\left(0.01 \mathrm{~V} \mathrm{~s}^{-1}, 298 \mathrm{~K}\right)$ for a Pd$\mathrm{Ru}$ alloy (99.3\% Pd in the bulk) and pure $\mathrm{Pd}$ in the potential region related to hydrogen electrosorption phenomena are shown in Fig. 1. The lines denoted with number (1) represent the voltammetric responses for fresh electrodes, i.e., just after their deposition. The lines denoted with (2) concern CVs for the same samples after the hydrogen pretreatment procedure involving several tens of repeated absorption/desorption cycles in the potential range between -0.10 and $0.38 \mathrm{~V}$ at $298 \mathrm{~K}$.

As for other Pd-based electrodeposits, the hydrogen pretreatment procedure leads to the improvement in kinetics of hydrogen electrosorption by Pd-Ru alloys, as compared with a freshly prepared electrode. Again, typically of a Pd alloy with another noble metal (e.g., Rh, Pt or Au), the course of a CV curve for a freshly deposited Pd-Ru alloy is more similar to the curve after the pretreatment procedure than in the case of pure $\mathrm{Pd}$, where the CVs recorded at these two stages of treatment are markedly different regarding the shape, height, and potentials of the hydrogen-related current signals. The effect of hydrogen treatment was thoroughly discussed in our previous papers [10, 29, 30] and explained mainly by defect creation and relaxation of the misfit strain energy at the interface resulting from the metal interactions with hydrogen [33, 34]. A conclusion was drawn that the second noble metal, such as $\mathrm{Ru}$, alloyed with Pd may accelerate the processes of phase transitions or surface kinetics of hydrogen electrosorption.

Since hydrogen pretreatment of fresh Pd-based electrodeposits is crucial to minimize the effects of further alloy aging during the hydrogen experiment proper, each alloy after its preparation was subjected to a series of voltammetric $\left(0.01 \mathrm{~V} \mathrm{~s}^{-1}\right)$

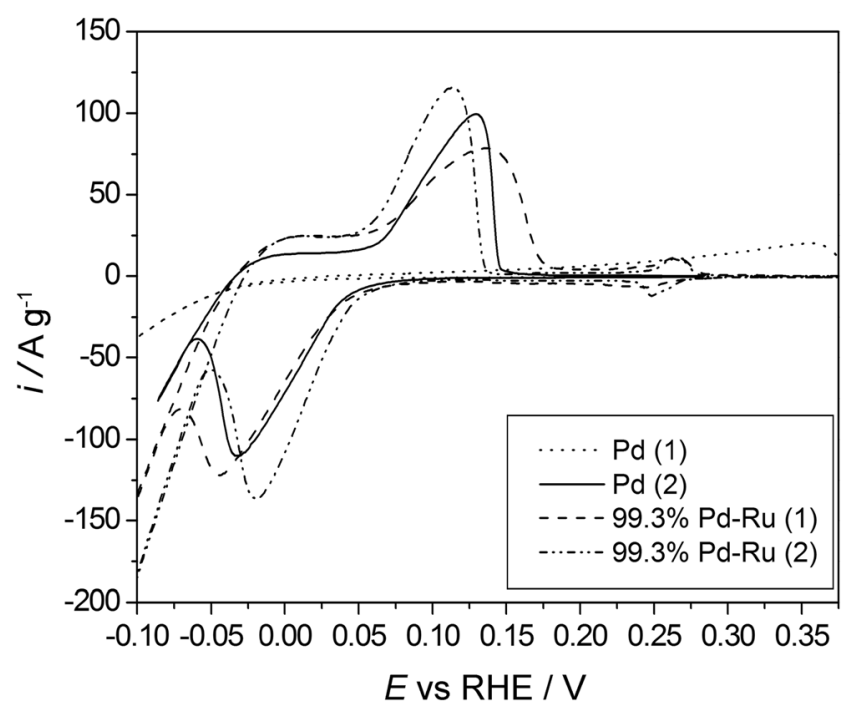

Fig. 1 The comparison of cyclic voltammograms (scan rate $0.01 \mathrm{~V} \mathrm{~s}^{-1}$, $298 \mathrm{~K}$ ) recorded for a pure Pd and a Pd-Ru alloy (99.3\% Pd in the bulk): both for freshly deposited layer - lines 1 and after $\mathrm{H}$ treatment - lines 2 (several tens of repeated absorption/desorption cycles in the potential range between -0.10 and $0.38 \mathrm{~V}$ at $298 \mathrm{~K}$ ) 
and chronoamperometric runs between -0.10 and $0.50 \mathrm{~V}$ at $298 \mathrm{~K}$, until a stable voltammogram was reached. Although the evolution of $\mathrm{CV}$ curves for hydrogen-treated $\mathrm{Pd}-\mathrm{Ru}$ electrodes was not shown earlier, it should be stressed that the same procedure was applied in all our previous works devoted to hydrogen electrosorption in Pd-Ru alloys [12-14, 28].

CV curves $\left(0.01 \mathrm{~V} \mathrm{~s}^{-1}\right)$ obtained at temperature range $283-$ $328 \mathrm{~K}$ in hydrogen electrosorption potential region for $\mathrm{Pd}$ and Pd-Ru alloys are presented in Fig. 2. For a detailed analysis of the nature of the hydrogen-related signals on CV curves recorded for Pd-based electrodes, we refer the reader to the literature [32]. Briefly, the large cathodic and anodic current peaks placed below ca $0.20 \mathrm{~V}$ correspond mainly to hydrogen absorption and its oxidative removal from the electrode bulk, while a pair of smaller peaks placed between 0.23 and $0.30 \mathrm{~V}$ (visible in Fig. 2b, c) originates mainly from surface processes of hydrogen adsorption/desorption.

One should note that two main factors influence the course of CVs in the hydrogen electrosorption potential region:

\section{Temperature}

Temperature influences the shape, height, and potential of both the cathodic (hydrogen electrosorption) and anodic peaks (oxidation of electrosorbed hydrogen). Namely, with increasing temperature, these signals become sharper and the potential difference between anodic and cathodic peaks decreases. Such tendencies mirror a greater degree of the electrochemical reversibility of the processes of hydrogen sorption/desorption at higher temperatures. Thus, the processes of hydrogen uptake and removal into/from $\mathrm{Pd}-\mathrm{Ru}$ alloys are accelerated as temperature rises.

Due to the fact that hydrogen electrosorption in $\mathrm{Pd}$ and its alloys is a multi-step process involving surface reaction, hydrogen transfer through the interface, its subsequent diffusion within metal bulk, and phase transitions between the phases of absorbed hydrogen, the exact result observed under given experimental conditions is the effect of the interplay between the influence of temperature, potential, and alloy composition on each of these steps. The point has been discussed in the literature [35, 36].

2. Alloy bulk composition

For each temperature studied, the main anodic peaks due to oxidation of electrosorbed hydrogen are shifted into lower potentials as the amount of Ru in the alloy bulk increases, while the position of the cathodic peaks is only slightly dependent on alloy bulk composition. The latter signal disappears for the alloys relatively rich in $\mathrm{Ru}$ (see CVs for $86.9 \%$ Pd-Ru in Fig. 2). According to our earlier findings, when $\mathrm{Ru}$ bulk content in the Pd-Ru alloy exceeds ca. 7\%, the $\beta$-phase of absorbed hydrogen is no longer formed and absorbed hydrogen exists only as a single $\alpha$-phase [12-14].
Fig. 2 Cyclic voltammogram (scan rate $0.01 \mathrm{~V} \mathrm{~s}^{-1}$ ) recorded for $\mathrm{Pd}$ and Pd-Ru alloys of different bulk compositions in the hydrogen electrosorption region at various temperatures. a $100 \%$ Pd. b $99.3 \%$ Pd-Ru. c $93.7 \%$ Pd-Ru. d $86.9 \%$ Pd-Ru
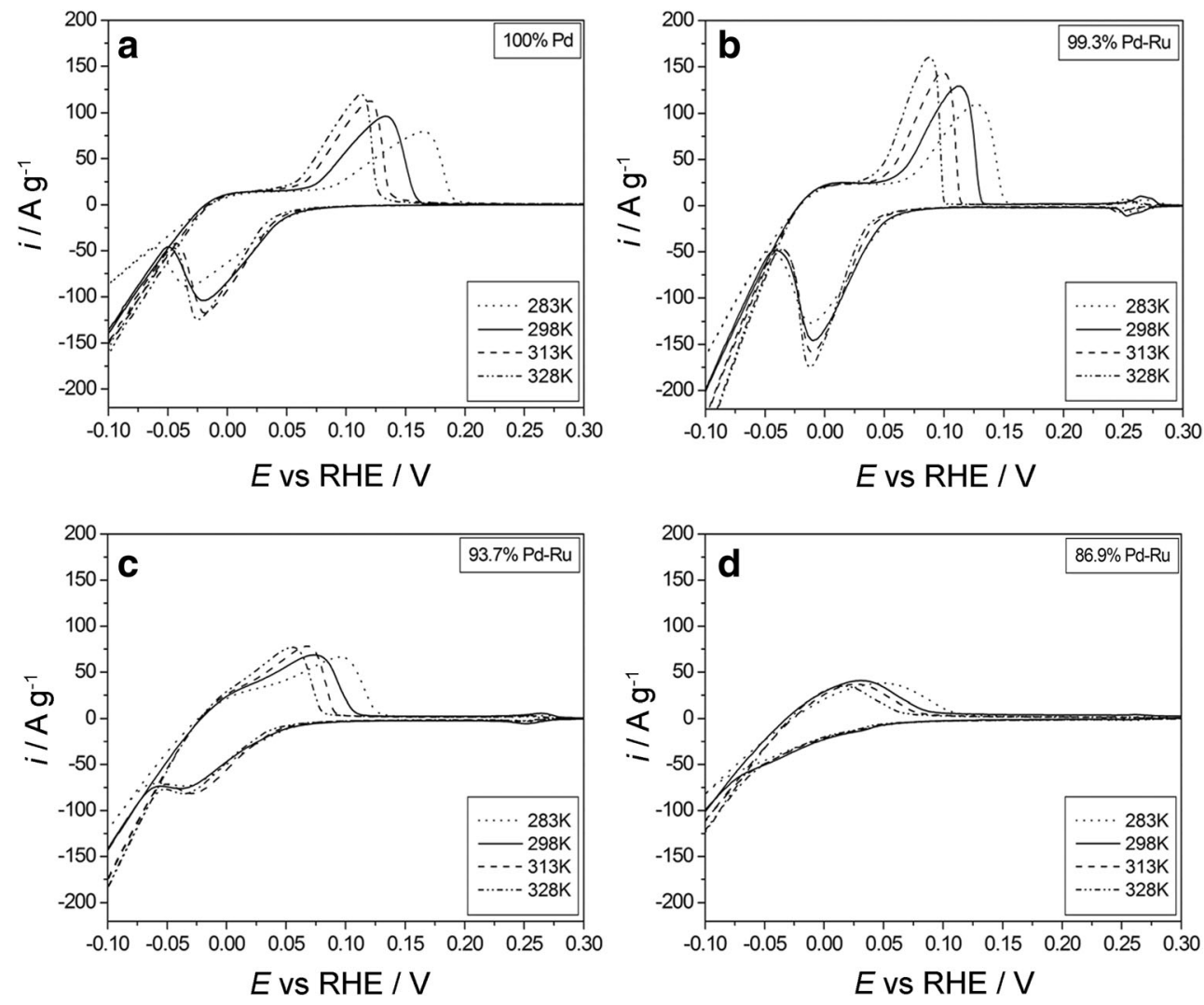
The effect of alloy bulk composition and temperature on the potential of the main anodic peak due to the oxidation of electrosorbed hydrogen $\left(E_{\mathrm{p}}^{\text {Hox }}\right)$ is shown in Fig. 3. The negative shift of $E_{\mathrm{p}}{ }^{\text {Hox }}$ with increasing both bulk Ru content and temperature is similar to the trends observed for Pd alloys with other noble metals [9, 10, 29-32].

The detailed analysis of the influence of alloy bulk composition on the potentials of hydrogen-related signals for Pd alloys is presented elsewhere [32]. A comparison of that effect for various Pd alloys is presented in Table 1 and in Fig. 8 at the end of this paper. It should be stressed that hydrogen desorption from all the alloys studied is kinetically facilitated in comparison with the situation for pure Pd, even if the trends in the changes in the thermodynamic functions describing the processes of hydrogen absorption/desorption may be opposite for Pd alloys with various noble metals [29-32].

Figure 4 shows the influence of temperature on the maximum amount of electrosorbed hydrogen in $\mathrm{Pd}$ and $\mathrm{Pd}-\mathrm{Ru}$ alloys of various bulk compositions. In all cases, the absorption capacity decreases with increasing temperature, as can be expected for an exothermic process $[1,36]$. Similarly to the analogous dependence reported for the Pd-Rh system [10], for $\mathrm{Pd}-\mathrm{Ru}$ alloys with different bulk compositions, different slopes of the H/M vs. T relationships are observed. The changes in these slopes with the amount of Ru in the alloy bulk can be attributed to the following factors, which are interrelated:

1. The values of enthalpy of hydride formation (more precisely, determined from van't Hoff plots as the enthalpy of the phase transition, $\Delta H_{\alpha-\beta}$ ) in Pd-Ru alloys change with alloy bulk composition, which affects the temperature effect on hydrogen absorption capacity for a given alloy composition [14]. However, since $\Delta H_{\alpha-\beta}$ becomes less

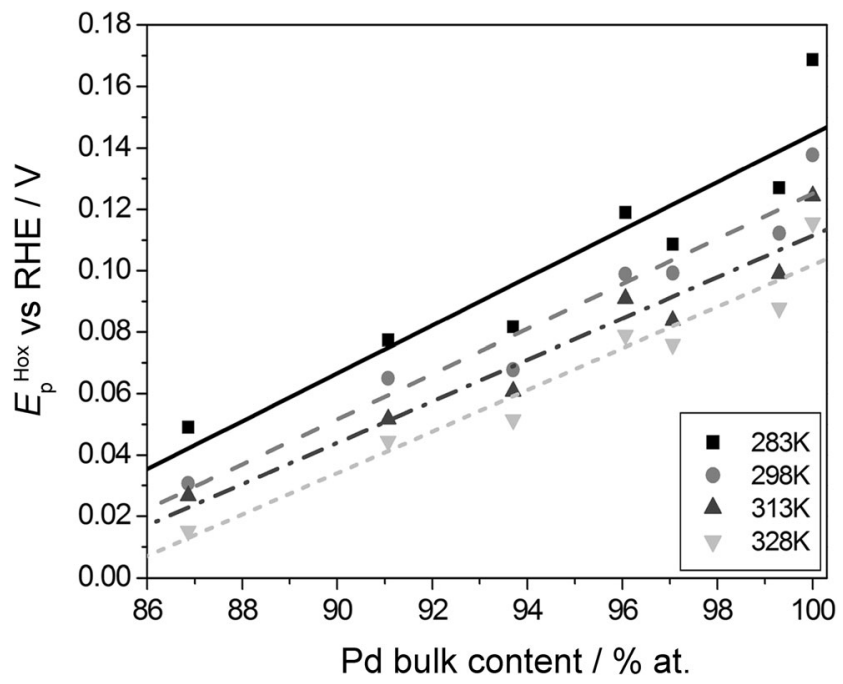

Fig. 3 Influence of Pd bulk content in Pd-Ru alloys on the potential of the main peak due to hydrogen oxidation $\left(E_{\mathrm{p}}{ }^{\mathrm{Hox}}\right)$ at various temperatures (from cyclic voltammetric data: electrosorption potential $-0.10 \mathrm{~V}$, scan rate $0.01 \mathrm{~V} \mathrm{~s}^{-1}$ )

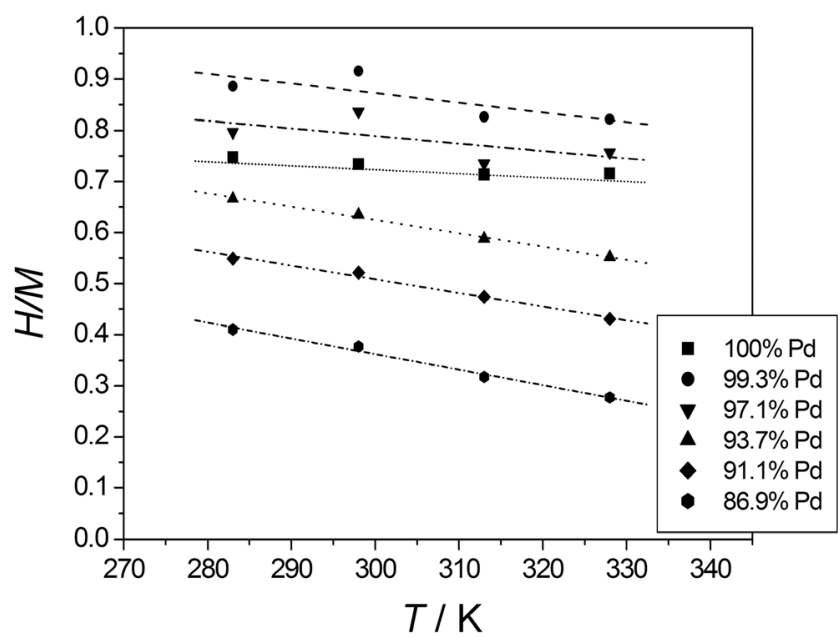

Fig. 4 Influence of temperature on the maximum amount of hydrogen electrosorbed in Pd and Pd-Ru alloys (from cyclic voltammetric data, scan rate $0.01 \mathrm{~V} \mathrm{~s}^{-1}$ )

and less negative (i.e., the process of the $\beta$-phase formation becomes less exothermic) with the increase in $\mathrm{Ru}$ bulk content, the greater effect of temperature on the maximum H/M ratio (i.e., higher slopes of the lines in Fig. 4) for Pd-Ru alloys than for pure Pd cannot alone be explained by those monotonic changes in $\Delta H_{\alpha-\beta}$.

2. The influence of temperature and alloy composition on the position of the H/M vs. potential curve on the potential axis (see then Fig. 5) and on the width of the two-phase region in the $\mathrm{Pd}-\mathrm{Ru}-\mathrm{H}$ system [13] has a significant impact on the amount of hydrogen electrosorbed at a given potential at different temperatures $[13,32]$. When temperature is low, hydrogen can be absorbed in the $\beta$-phase at sufficiently low potentials, while for the same alloy at elevated temperature, pure $\beta$-phase is no longer formed and absorbed hydrogen exists as a mixture of the $\alpha$ - and $\beta$ phases or as the $\alpha$-phase only. Thus, at different temperatures, the maximum hydrogen absorption capacity of a given alloy may be related to different phases of absorbed hydrogen, whose hydrogen capacities are markedly different. Moreover, one should also remember that when the effect of temperature concerns the single $\alpha$-phase, the values of enthalpy of that phase formation is different from $\Delta H_{\alpha-\beta}$ considered above and the effect on $\mathrm{H} / \mathrm{M}$ vs. $\mathrm{T}$ dependence originating from enthalpy changes with temperature may here be different than that for the $\beta$-phase.

The effect of electrode potential, temperature, and alloy bulk composition on the amount of electrosorbed hydrogen is shown in Fig. 5. The experimental procedures and data treatment were described in our previous papers [8-10, 12-14, 29-32], where also the detailed analysis of this kind of plots was presented.

Here, one should pay attention to the region with a sharp increase in the hydrogen absorption capacity, corresponding 
Fig. 5 Influence of electrosorption potential and temperature on the amount of hydrogen electrosorbed in $\mathrm{Pd}$ and Pd-Ru alloys. a $100 \%$ Pd. b 99.3\% Pd-Ru. c 96.1\% Pd-Ru. d 93.7\% Pd-Ru. Absorption course (solid symbol and solid lines); desorption course (from chronoamperometric data) (open symbols and dashed lines)
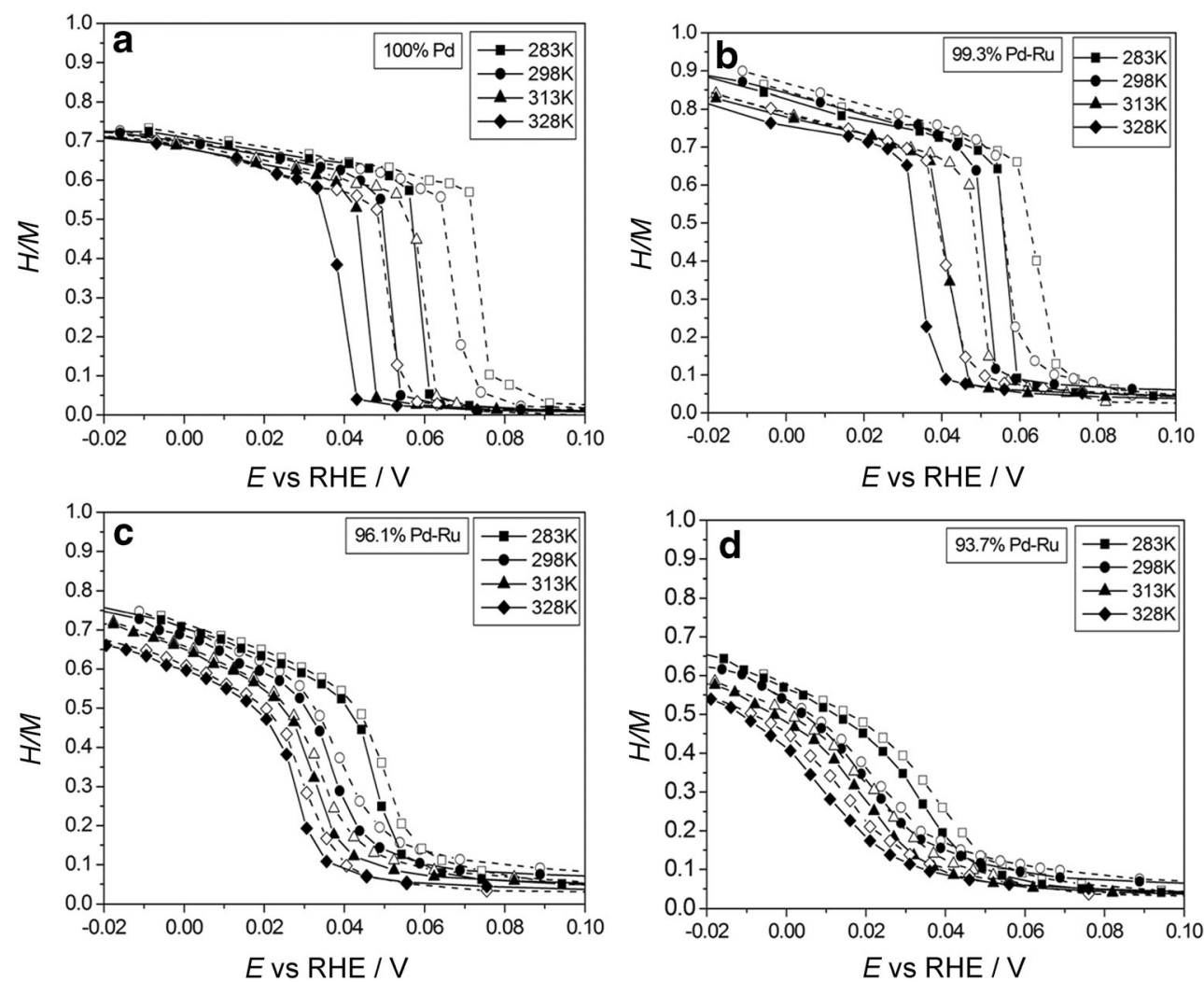

to the $\alpha \rightarrow \beta$ and $\beta \rightarrow \alpha$ phase transitions during absorption and desorption, respectively. The potentials of the phase transitions $\left(E_{\alpha-\beta}, E_{\beta-\alpha}\right)$ are shifted negatively with increasing temperature. This trend is well visible in Fig. 6, where the values of $E_{\alpha-\beta}$ and $E_{\beta-\alpha}$ are recalculated into the Gibbs free energy of the hydride phase formation/decomposition (in fact, the respective functions of phase transitions, $\Delta G_{\alpha-\beta}$ and $\left.\Delta G_{\beta-\alpha}\right)$.

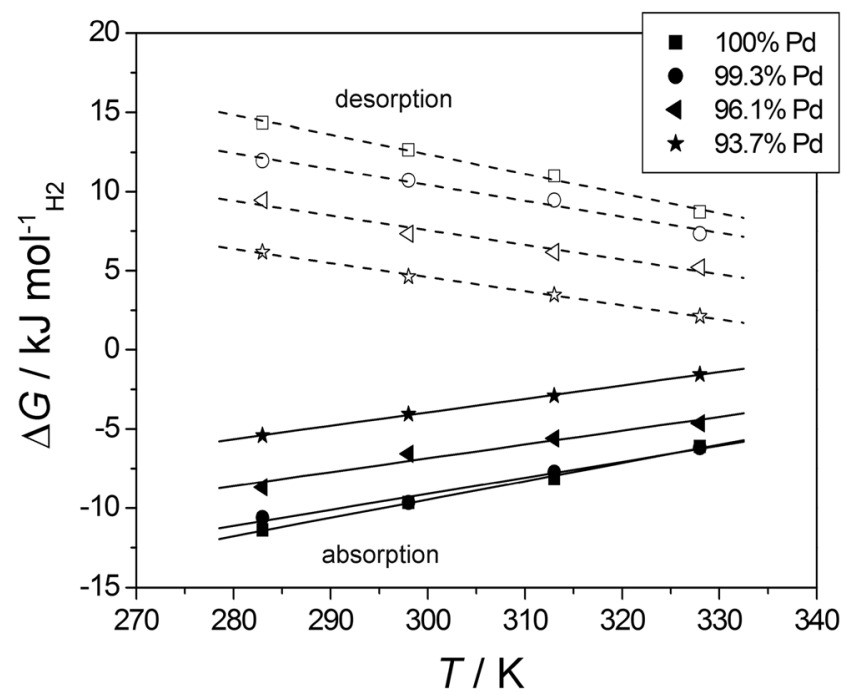

Fig. 6 Influence of temperature on the values of Gibbs free energy of the $\beta$-phase formation and decomposition $\left(\Delta G_{\alpha-\beta}\right.$ and $\left.\Delta G_{\beta-\alpha}\right)$ in Pd and Pd$\mathrm{Ru}$ alloys of different bulk compositions. Absorption course (solid symbol and solid lines); desorption course (from chronoamperometric data) (open symbols and dashed lines)
With increasing temperature, the values of $\Delta G_{\alpha-\beta}$ become less negative and the values of $\Delta G_{\beta-\alpha}$ become less positive, which means that at elevated temperatures, the $\beta$-phase becomes thermodynamically less stable. More information of the thermodynamics of hydrogen absorption in Pd-Ru and other alloys was given in our recent papers [14, 37].

A decrease in the absolute values of both $\Delta G_{\alpha-\beta}$ and $\Delta G_{\beta-\alpha}$ is also observed with an increase in $\mathrm{Ru}$ bulk content in Pd-Ru alloys. This effect originates from the crystal lattice

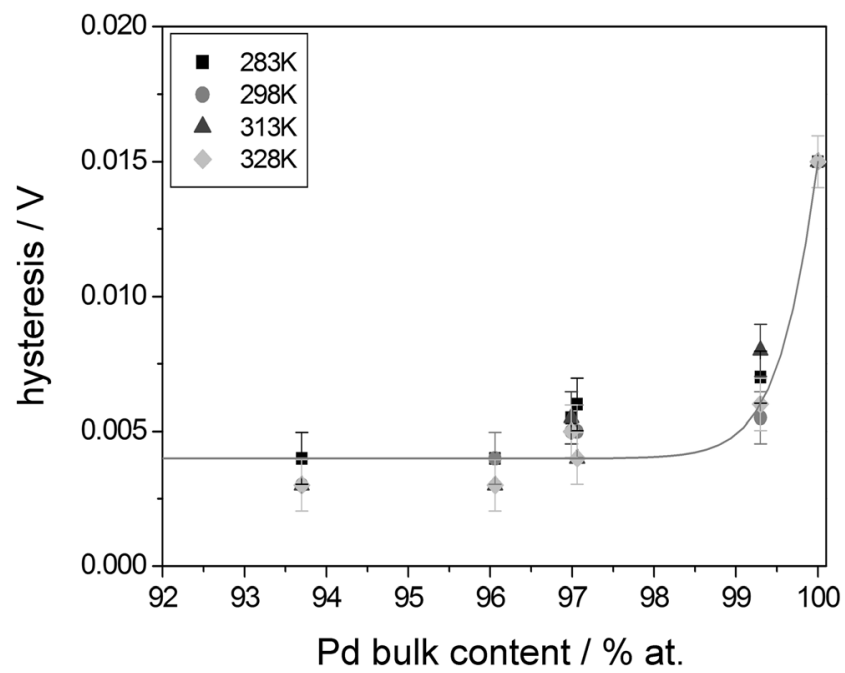

Fig. 7 Influence of Pd content in the alloy bulk on the extent of the absorption/desorption hysteresis at various temperatures (from chronoamperometric data) 
contraction after Pd alloying with Ru (geometric effect) [28]. On the other hand, the electronic effect, concerning an increase in the number of gaps in the Pd d-band around and below Pd Fermi level, is responsible for a higher hydrogen absorption capacity of Pd-Ru alloys containing less than ca. $3 \% \mathrm{Ru}$ in the bulk (with a sharp maximum of the $\mathrm{H} / \mathrm{M}$ ratio for ca. $1 \%$ at. $\mathrm{Ru})$, as compared with the capacity of pure $\mathrm{Pd}[16$, 38, 39].

Figure 7 shows the influence of temperature and alloy bulk composition on the extent of the absorption/desorption hysteresis, i.e., the difference between $E_{\alpha-\beta}$ and $E_{\beta-\alpha}$ [1]. The hysteresis strongly depends on Pd bulk content in Pd-rich Pd-Ru

Table 1 Comparison of the effect of temperature and alloy bulk composition on the processes of hydrogen electrosorption in Pd-binary alloys (based on this work and refs. [10,28-32])

\begin{tabular}{|c|c|c|c|c|}
\hline & $\mathrm{Pd}-\mathrm{Ru}$ & $\mathrm{Pd}-\mathrm{Rh}$ & $\mathrm{Pd}-\mathrm{Pt}$ & $\mathrm{Pd}-\mathrm{Au}$ \\
\hline \multicolumn{5}{|c|}{ Effect of increasing temperature (in the range $283-328 \mathrm{~K}$ ) on } \\
\hline $\begin{array}{l}\text { Maximum hydrogen solubility in the } \\
\beta \text {-phase }\end{array}$ & Decreased & Decreased & Decreased & Decreased \\
\hline Thermodynamic stability of the $\beta$-phase & Decreased & Decreased & Decreased & Decreased \\
\hline Absorption/desorption hysteresis & Slightly reduced & Slightly reduced & Slightly reduced & Slightly reduced \\
\hline $\begin{array}{l}\text { Extent of the two-phase region in the } \\
\text { Pd-metal-H system }\end{array}$ & $\begin{array}{l}\text { Decreased but not } \\
\text { completely reduced }\end{array}$ & $\begin{array}{l}\text { Decreased but not } \\
\text { completely reduced }\end{array}$ & $\begin{array}{l}\text { Decreased but not } \\
\text { completely reduced }\end{array}$ & $\begin{array}{l}\text { Decreased but not } \\
\text { completely reduced }\end{array}$ \\
\hline $\begin{array}{l}\text { Kinetics of hydrogen } \\
\text { electrosorption/desorption }\end{array}$ & Facilitated & Facilitated & Facilitated & Facilitated \\
\hline $\begin{array}{l}\text { Potential of main peak cathodic due to } \\
\text { hydrogen electrosorption }(\mathrm{CV}, \\
\left.0.01 \mathrm{~V} \mathrm{~s}^{-1}, 298 \mathrm{~K}\right)\end{array}$ & Slightly increased & No distinct effect & No distinct effect & No distinct effect \\
\hline $\begin{array}{l}\text { Potential of main anodic peak due to } \\
\text { oxidation of electrosorbed hydrogen } \\
\left(\mathrm{CV}, 0.01 \mathrm{~V} \mathrm{~s}^{-1}, 298 \mathrm{~K}\right)\end{array}$ & Decreased & Decreased & Decreased & Decreased \\
\hline $\begin{array}{l}\text { Degree of electrochemical reversibility of } \\
\text { hydrogen absorption/desorption }\end{array}$ & Greater & Greater & Greater & Greater \\
\hline \multicolumn{5}{|c|}{ Effect of increasing alloying metal bulk content on } \\
\hline $\begin{array}{l}\text { Lattice parameter after second metal } \\
\text { additive to Pd - type of alloy }\end{array}$ & Decreased-contracted & Decreased-contracted & Increased-expanded $^{\mathrm{a}}$ & Increased-expanded \\
\hline $\begin{array}{l}\text { Hydrogen solubility in the saturated } \\
\beta \text {-phase }(298 \mathrm{~K})\end{array}$ & $\begin{array}{l}\text { Maximum solubility for } \\
\text { ca. } 1 \% \mathrm{Ru}\end{array}$ & $\begin{array}{l}\text { Maximum solubility for } \\
\text { ca. } 6-8 \% \mathrm{Rh}\end{array}$ & Monotonic decrease & Monotonic decrease \\
\hline Thermodynamic stability of the $\beta$-phase & Decreased & Decreased & Decreased & Increased \\
\hline$\alpha-\beta$ phase transition potential $(298 \mathrm{~K})$ & $\begin{array}{l}\text { Decreased by ca. } 4.4 \mathrm{mV} \\
\text { per } 1 \% \text { of } \mathrm{Ru}\end{array}$ & $\begin{array}{l}\text { Decreased by ca. } 2.8 \mathrm{mV} \\
\text { per } 1 \% \text { of Rh }\end{array}$ & $\begin{array}{l}\text { Decreased by ca. } 2.9 \mathrm{mV} \\
\text { per } 1 \% \text { of } \mathrm{Pt}\end{array}$ & $\begin{array}{l}\text { Increased by ca. } 0.7 \mathrm{mV} \\
\text { per } 1 \% \text { of } \mathrm{Au}\end{array}$ \\
\hline Enthalpy of the a- $\beta$-phase transition ${ }^{\mathrm{b}}$ & Increased & Increased & Increased & Decreased \\
\hline Entropy of the $\alpha-\beta$ phase transition ${ }^{c}$ & Increased & No distinct effect & Increased & No distinct effect \\
\hline $\begin{array}{l}\text { Extent of the absorption/desorption hys- } \\
\text { teresis }(298 \mathrm{~K})\end{array}$ & $\begin{array}{c}\text { Decreased to }<4 \mathrm{mV} \\
\text { above ca. } 4 \% \mathrm{Ru}\end{array}$ & $\begin{array}{l}\text { Decreased to }<4 \mathrm{mV} \\
\text { above ca. } 12 \% \mathrm{Rh}\end{array}$ & $\begin{array}{l}\text { Decreased to }<4 \mathrm{mV} \\
\text { above ca. } 8 \% \mathrm{Pt}\end{array}$ & $\begin{array}{r}\text { Decreased to }<4 \mathrm{mV} \\
\text { above ca. } 15 \% \mathrm{Au}\end{array}$ \\
\hline $\begin{array}{l}\text { Extent of the two-phase region in the } \\
\text { Pd-metal-H system }\end{array}$ & $\begin{array}{l}\text { Decreased and finally } \\
\text { completely reduced } \\
\text { above ca. } 7 \% \mathrm{Ru}\end{array}$ & $\begin{array}{l}\text { Decreased and finally } \\
\text { completely reduced } \\
\text { above ca. } 25 \% \mathrm{Rh}\end{array}$ & $\begin{array}{l}\text { Decreased and finally } \\
\text { completely reduced } \\
\text { above ca. } 15 \% \mathrm{Pt}\end{array}$ & $\begin{array}{l}\text { Decreased and finally } \\
\text { completely reduced } \\
\text { above ca. } 22 \% \mathrm{Au}\end{array}$ \\
\hline $\begin{array}{l}\text { Kinetics of hydrogen } \\
\text { electrosorption/desorption }\end{array}$ & Facilitated & Facilitated & Facilitated & Facilitated \\
\hline $\begin{array}{l}\text { Degree of electrochemical reversibility of } \\
\text { hydrogen absorption/desorption }\end{array}$ & Greater & Greater & Greater & Greater \\
\hline $\begin{array}{l}\text { Potential of main cathodic peak due to } \\
\text { hydrogen electrosorption (CV, } \\
\left.0.01 \mathrm{~V} \mathrm{~s}^{-1}, 298 \mathrm{~K}\right)\end{array}$ & No distinct effect & Decreased & No distinct effect & Increased \\
\hline $\begin{array}{l}\text { Potential of main anodic peak due to } \\
\text { oxidation of electrosorbed hydrogen } \\
\left(\mathrm{CV}, 0.01 \mathrm{~V} \mathrm{~s}^{-1}, 298 \mathrm{~K}\right)\end{array}$ & $\begin{array}{l}\text { Decreased by ca. } 7.7 \mathrm{mV} \\
\text { per } 1 \% \text { of } \mathrm{Ru}\end{array}$ & $\begin{array}{l}\text { Decreased by ca. } 3.3 \mathrm{mV} \\
\text { per } 1 \% \text { of } \mathrm{Rh}\end{array}$ & $\begin{array}{l}\text { Decreased by ca. } 5.6 \mathrm{mV} \\
\text { per } 1 \% \text { of } \mathrm{Pt}\end{array}$ & $\begin{array}{l}\text { Decreased by ca. } 2.2 \mathrm{mV} \\
\text { per } 1 \% \text { of } \mathrm{Au}\end{array}$ \\
\hline
\end{tabular}

${ }^{a}$ Although Pt-Pd alloys are slightly expanded systems, their behavior in the process of hydrogen absorption is exceptional and follows the trends typical of contracted alloys

${ }^{b}$ Enthalpy of the a- $\beta$-phase transition in Pd-rich alloys is a negative value; therefore, its increase/decrease after the additive of alloying metals means that the values become less/more negative (i.e., the absolute values become smaller/greater), respectively

${ }^{\mathrm{c}}$ Entropy of the a- $\beta$-phase transition in Pd-rich alloys is a negative value; therefore, its increase/decrease after the additive of alloying metals means that the values become less/more negative (i.e., the absolute values become smaller/greater), respectively 
alloys and decreases from $16 \mathrm{mV}$ for pure Pd to ca. $4 \mathrm{mV}$ with $\mathrm{Ru}$ additive of only $4 \%$. The remaining residual hysteresis for $\mathrm{Pd}-\mathrm{Ru}$ alloys with higher amounts of $\mathrm{Ru}$ is likely to be an overestimation originating from difficulties in separation of the currents due to hydrogen electrosorption and evolution, which are more strongly overlapped for the alloys containing more Ru (see [6]).

The hysteresis decrease with increasing bulk amount of $\mathrm{Ru}$ is in line with the miscibility gap reduction in the Pd-Ruhydrogen system reported earlier [13]. In the temperature range studied, the hysteresis very weakly depends on temperature; nevertheless, a small reduction of hysteresis is yet visible, which is again consistent with the fact that an increase in temperature makes the two-phase region in the Pd-metal-hydrogen system narrower [1].

In Table 1, we have compared our data on the influence of temperature and alloy bulk composition on the processes of hydrogen electrosorption in Pd binary alloys with $\mathrm{Ru}, \mathrm{Rh}, \mathrm{Pt}$, and $\mathrm{Au}$ [8-10, 12-14, 29-32]. In particular, one should note that some aspects of the electrosorption processes are influenced qualitatively in the same manner by the increase in both temperature and second metal bulk content, namely the
Fig. 8 a The values of a mean slope (expressed in $\mathrm{mV}$ per one atomic percent of bulk content of second metal additive) of the temperature dependence of the potentials of the main peak of electrosorbed hydrogen oxidation $-E_{\mathrm{p}}^{\text {Hox }}$ (from cyclic voltammetric data: scan rate $\left.0.01 \mathrm{~V} \mathrm{~s}^{-1}, 298 \mathrm{~K}\right)$ and the $\alpha-\beta$ phase transition $-E_{\alpha-\beta}$ (from chronoamperometric data, 298 K), for various Pd-noble metal alloys. $\mathbf{b}$ The values of the limiting bulk content of second metal additive needed for the hysteresis reduction below $4 \mathrm{mV}$ and the miscibility gap disappearance in various Pd-noble metal-hydrogen systems (from chronoamperometric data, $298 \mathrm{~K}$ ) b

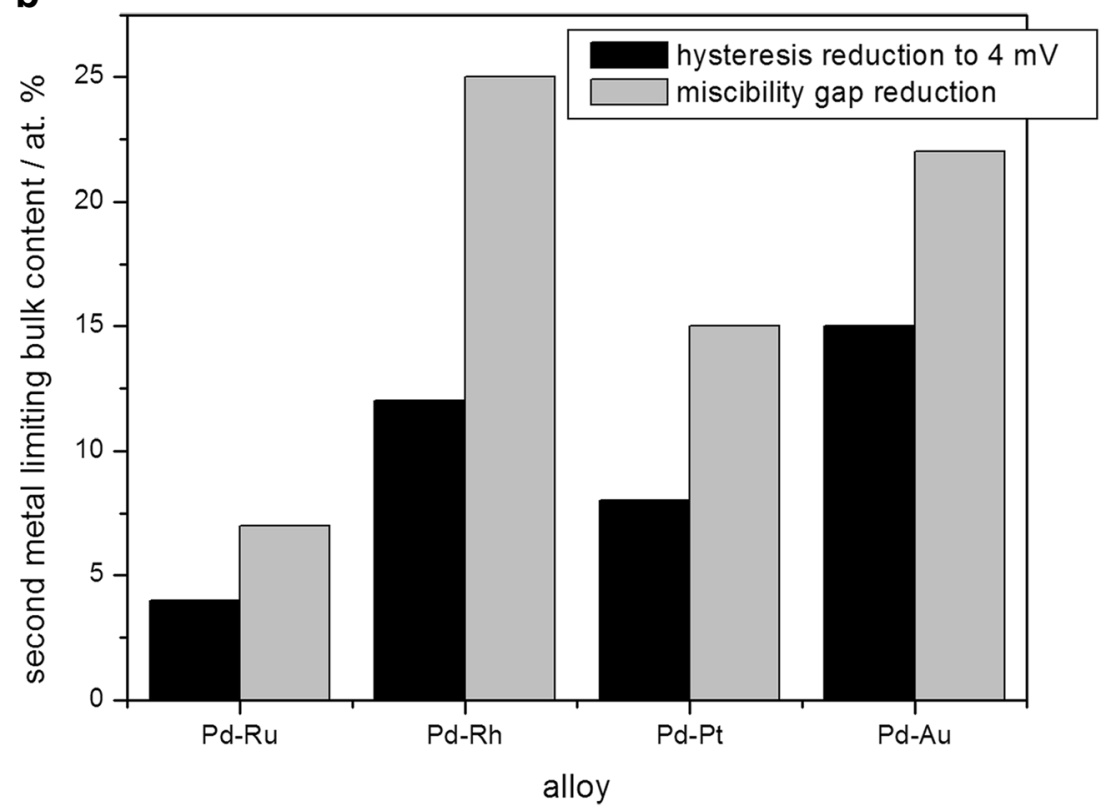


kinetics of absorbed hydrogen oxidation is facilitated, and the miscibility gap in the Pd-metal-hydrogen system as well as hysteresis is reduced.

However, Fig. 8 shows that from the quantitative point of view, the influence of alloy bulk composition on these parameters may be markedly different for various alloying metals. It is noteworthy that the additive of Ru has the strongest effect on the changes in $E_{\mathrm{p}}{ }^{\mathrm{Hox}}, E_{\alpha-\beta}$ and $E_{\beta-\alpha}$. Moreover, also in the case of the Pd-Ru system, the smallest Ru additive is needed for the miscibility gap to disappear and hysteresis to be reduced. This behavior indicates that the presence of even minor amounts of Ru markedly modifies the properties of Pd in the alloy of these metals. As we mentioned in our earlier reports [12-14], such a situation is probably due to a significant alteration of the alloy electronic structure. In the other Pd-based system exhibiting a similar behavior, i.e., Pd-Rh, the effect of the bulk content of the additive metal is not as strong and the alloy composition range corresponding to the enhanced ability to absorb hydrogen is broader (up to ca. $20 \%$ at. Rh), as compared to a very narrow range of compositions for Pd-Ru alloys (less than 3\% at. Ru) absorbing more hydrogen than pure $\mathrm{Pd}$.

The additive of any amounts of Pt to Pd leads to a deterioration of the maximum hydrogen absorption capacity and makes the $\beta$-phase thermodynamically less stable; however, it has the most favorable effect on hydrogen electrosorption kinetics and hysteresis reduction of all noble metals. On the other hand, the presence of $\mathrm{Au}$ in Pd alloys has usually the weakest effect on the above parameters from all types of the alloys studied here. Other comparisons between the behavior of Pd-noble metal alloys toward hydrogen were presented in other papers devoted to the thermodynamic functions of hydride formation/ decomposition [14, 29, 30, 37], the nature of hydrogen-related electrochemical signals [32], and the properties of these materials as electrodes for electrochemical capacitors [40].

\section{Conclusions}

Increasing temperature in the range $283-328 \mathrm{~K}$ results in the following changes in hydrogen electrosorption properties of Pd-Ru alloys:

(a) A decrease in the maximum ability to absorb hydrogen.

(b) A decrease in the thermodynamic stability of the $\beta$ phase.

(c) A slight reduction in the extent of absorption/desorption hysteresis and miscibility gap in the Pd-Ru-H system.

(d) An acceleration of hydrogen electrosorption and desorption, leading to a greater degree of electrochemical reversibility of these processes.

For a given temperature, increasing Ru bulk content in Pd$\mathrm{Ru}$ alloys results in: (a) An increase in the maximum ability to absorb hydrogen for Pd-Ru alloys containing in the bulk ca. $1 \%$ at. $\mathrm{Ru}$, followed by a sharp deterioration of the absorption properties with a greater Ru additive (above $3 \%$ at.).

(b) A decrease in the thermodynamic stability of the $\beta$ phase.

(c) A significant decrease in the extent of absorption/ desorption hysteresis, which becomes reduced to ca. $4 \mathrm{mV}$ after the additive of ca. $4 \% \mathrm{Ru}$.

(d) A complete disappearance of the two-phase region in the $\mathrm{Pd}-\mathrm{Ru}-\mathrm{H}$ system for Pd-Ru alloys containing more than ca. $7 \% \mathrm{Ru}$ in the bulk.

(e) An acceleration of hydrogen electrosorption and desorption, leading to a greater degree of electrochemical reversibility of these processes.

Among various Pd-binary alloys with noble metals studied in our laboratory, hydrogen electrosorption properties of the $\mathrm{Pd}-\mathrm{Ru}$ system alter the most strongly with the variation of the second metal bulk content.

Funding information This work was financially supported by NCN (National Science Centre, Poland), grant no. 2011/01/N/ST4/02285 and grant no. 2015/17/ B/ST8/03377.

Open Access This article is distributed under the terms of the Creative Commons Attribution 4.0 International License (http:// creativecommons.org/licenses/by/4.0/), which permits unrestricted use, distribution, and reproduction in any medium, provided you give appropriate credit to the original author(s) and the source, provide a link to the Creative Commons license, and indicate if changes were made.

\section{References}

1. F.A. Lewis, The palladium/hydrogen system (Academic Press, New York, 1967)

2. G. Alefeld, J. Völkl (eds.), Hydrogen in metals (Springer-Verlag, Berlin, 1978)

3. G. Jerkiewicz, Prog. Surf. Sci. 57, 137 (1998)

4. G. Jerkiewicz, Electrocatalysis 1(4), 179 (2010)

5. A. Zalineeva, S. Baranton, C. Coutanceau, G. Jerkiewicz, Langmuir 31, 1605 (2015)

6. A. Zalineeva, S. Baranton, C. Coutanceau, G. Jerkiewicz, Sci. Adv. 3, e1600542 (2017)

7. N. Comisso, A. De Ninno, E. Del Giudice, G. Mengoli, P. Soldan, Electrochim. Acta 49, 1379 (2004)

8. A. Żurowski, M. Łukaszewski, A. Czerwiński, Electrochim. Acta 51, 3112 (2006)

9. U. Koss, M. Łukaszewski, K. Hubkowska, A. Czerwiński, J. Solid State Electrochem. 15, 2477 (2011)

10. U. Koss, K. Hubkowska, M. Łukaszewski, A. Czerwiński, Electrochim. Acta 107, 269 (2013)

11. Y. Sakamoto, Y. Haraguchi, M. Ura, F.L. Chen, Ber. Bunsenges. Phys. Chem. 98, 964 (1994)

12. K. Hubkowska, M. Łukaszewski, A. Czerwiński, Electrochem. Commun. 20, 175 (2012)

13. K. Hubkowska, U. Koss, M. Łukaszewski, A. Czerwiński, J. Electroanal. Chem. 704, 10 (2013) 
14. K. Hubkowska, M. Łukaszewski, A. Czerwiński, Electrochem. Commun. 48, 40 (2014)

15. Y. Sakamoto, F.L. Chen, M. Ura, T.B. Flanagan, Ber. Bunsenges. Phys. Chem. 99, 807 (1995)

16. E. Wicke, K. Frölich, Z. Phys, Chem. N. F. 163, 35 (1989)

17. K. Kandasamy, F.A. Lewis, W.D. McFall, R.-A. McNicholl, Z. Phys, Chem. N. F. 163, 41 (1989)

18. F.A. Lewis, Plat. Met. Rev. 5, 21 (1961)

19. T.B. Flanagan, Y. Sakamoto, Plat. Met. Rev. 37, 26 (1993)

20. M. Łukaszewski, M. Grdeń, A. Czerwiński, J. Phys. Chem. Solids 65, 523 (2004)

21. M. Łukaszewski, M. Grdeń, A. Czerwiński, Anal. Lett. 37, 967 (2004)

22. M. Łukaszewski, M. Grdeń, A. Czerwiński, Electrochim. Acta. 49, 3161 (2004)

23. L. Sun, D. Cao, G. Wang, J. Appl. Electrochem. 38, 1415 (2008)

24. J. Bagchi, S.K. Bhattacharya, Transit. Met. Chem. 32, 47 (2007)

25. Z. Bai, L. Yang, J. Zhang, L. Li, J. Lv, C. Hu, J. Zhou, Catal Commun. 11, 919 (2010)

26. P. Kędzierzawski, A. Mikołajczuk, A. Borodziński, B. Mierzwa, L. Stobiński, ECS Trans. 28, 23 (2010)

27. A.L. Cabrera, E. Morales-Leal, Catal. Lett. 30, 11 (1995)

28. K. Hubkowska, U. Koss, M. Łukaszewski, A. Czerwiński, Electrochim. Acta 132, 214 (2014)
29. K. Hubkowska, M. Łukaszewski, A. Czerwiński, Electrochim. Acta 56, 235 (2010)

30. K. Hubkowska, M. Łukaszewski, A. Czerwiński, Electrochim. Acta 56, 2344 (2011)

31. M. Łukaszewski, K. Hubkowska, A. Czerwiński, J. Electroanal. Chem. 651, 131 (2011)

32. M. Łukaszewski, K. Hubkowska, U. Koss, A. Czerwiński, Materials 6, 4817 (2013)

33. P. Millet, M. Srour, R. Faure, R. Durand, Electrochem. Commun. 3, 478 (2001)

34. K. Sakaki, T. Yamada, M. Mizuno, H. Araki, Y. Shirai, Mater. Trans. 43(11), 2652 (2002)

35. W.S. Zhang, X.W. Zhang, X.G. Zhao, J. Electroanal. Chem. 458, 107 (1998)

36. A. Czerwiński, I. Kiersztyn, M. Grdeń, J. Solid State Electroanal. 7, $321(2003)$

37. U. Koss, M. Łukaszewski, K. Hubkowska, A. Czerwiński, J. Electroanal. Chem. 756, 124 (2015)

38. K. Frölich, H.G. Severin, R. Hempelmann, E. Wicke, Z. Phys, Chem. N. F. 119, 33 (1980)

39. E. Wicke, J. Less-Common Met. 74, 185 (1980)

40. M. Łukaszewski, K. Hubkowska, U. Koss, A. Czerwiński, J. Solid State, Electrochem 16, 2533 (2012) 